San Jose State University

SJSU ScholarWorks

Master's Projects

Master's Theses and Graduate Research

$5-1-2006$

\title{
How Special Education Teachers of High School-Aged Students Address Sex Education
}

Amelia Owen-Casillas

San Jose State University

Follow this and additional works at: https://scholarworks.sjsu.edu/etd_projects

Part of the Pediatric Nursing Commons

\section{Recommended Citation}

Owen-Casillas, Amelia, "How Special Education Teachers of High School-Aged Students Address Sex Education" (2006). Master's Projects. 802.

DOI: https://doi.org/10.31979/etd.qst4-ncmu

https://scholarworks.sjsu.edu/etd_projects/802

This Master's Project is brought to you for free and open access by the Master's Theses and Graduate Research at SJSU ScholarWorks. It has been accepted for inclusion in Master's Projects by an authorized administrator of SJSU ScholarWorks. For more information, please contact scholarworks@sjsu.edu. 


\section{SAN JOSE STATE UNIVERSITY \\ SCHOOL OF NURSING}

\section{MASTER'S PROGRAM PROJECT OPTION (PLAN B) PROJECT SIGNATURE FORM}

STUDENT NAME___ Amelia Owen-Casillas

SEMESTER ENROLLED___ Spring 2006

TITLE OF PROJECT_HOW SPECIAL EDUCATION TEACHERS

OF HIGH SCHOOL-AGED STUDENTS ADDRESS SEX

EDUCATION

NAME OF JOURNAL___Journal of School Nursing

The project and manuscript have been successfully completed and meet the standards of the School of Nursing at San Jose State University. The project demonstrates the application of professional knowledge, clinical expertise, and scholarly thinking. An abstract of the project and two copies of the manuscript are attached.

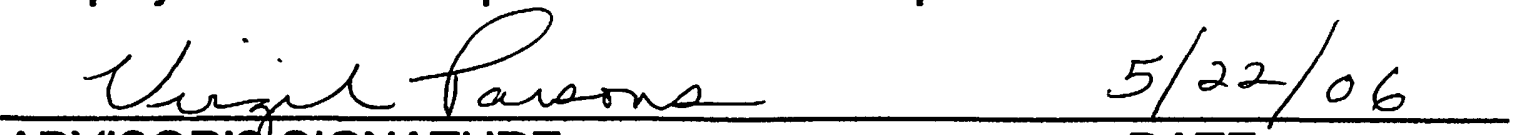
ADVISOR'S SIGNATURE DATE

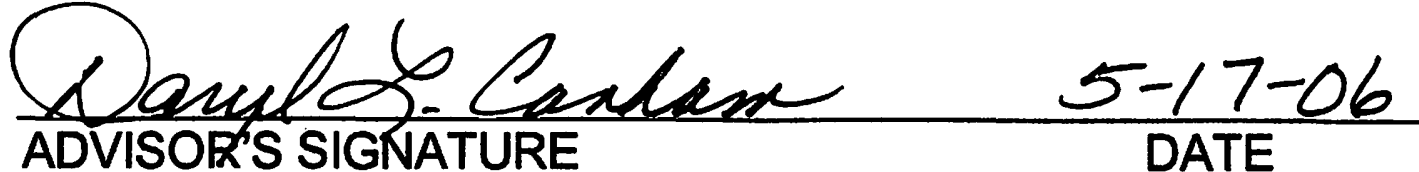

Please submit this form to the Graduate Coordinator. Attach abstract, two copies of the manuscript, and documentation of submission to the journal (i.e., Postal receipt) 


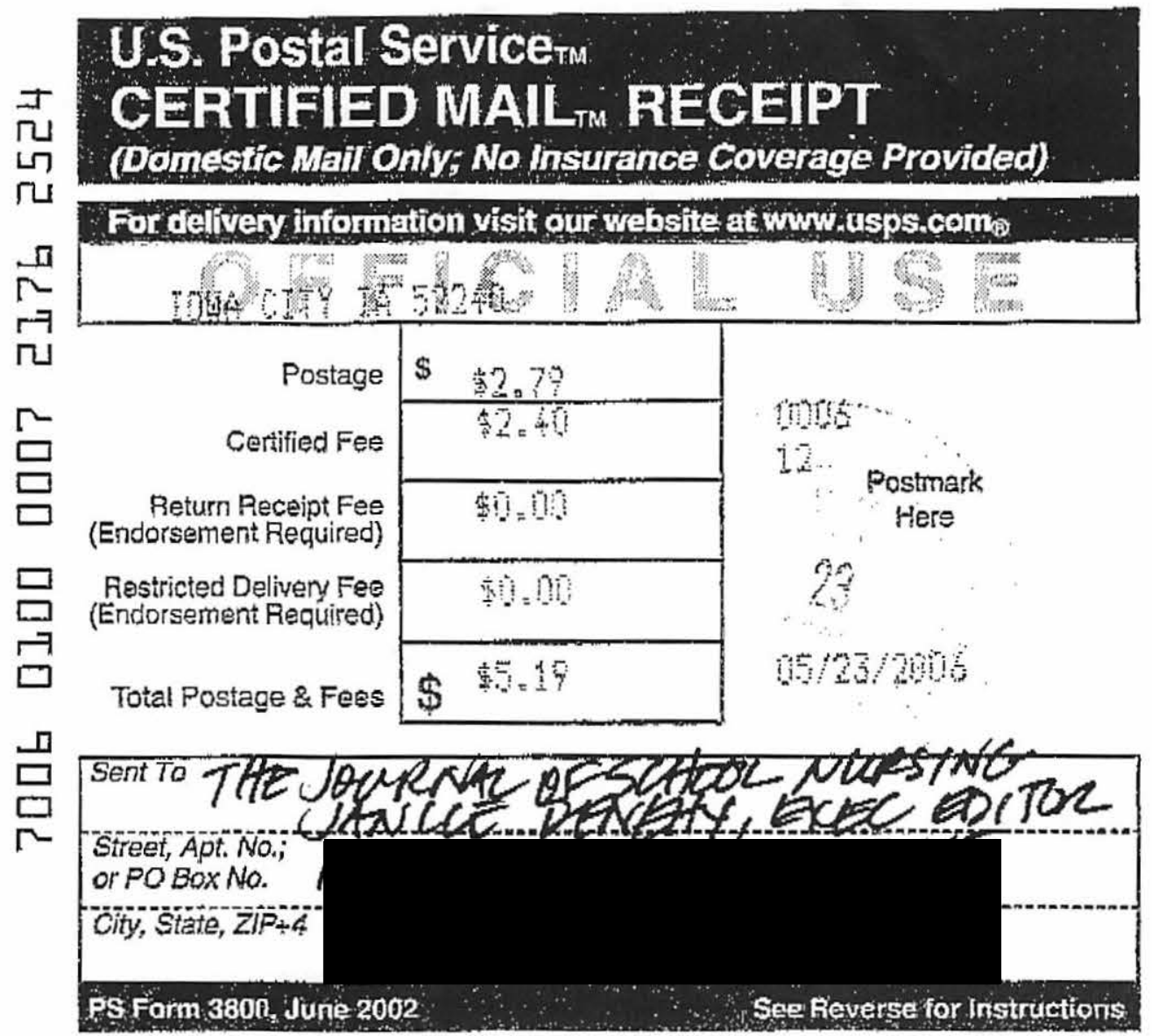




\title{
HOW SPECIAL EDUCATION TEACHERS OF HIGH SCHOOL-AGED STUDENTS ADDRESS SEX EDUCATION
}

\begin{abstract}
In this qualitative pilot study, five special education teachers of high-school-age students responded to seven research questions regarding how they address sex education, a part of family living from the Health Framework for California Public Schools. The participating special education teachers taught either in special education programs for the emotionally-disturbed(ED) or severely handicapped (SH). An overall identified theme for both groups of teachers was family participation. Other themes were teachers needing to be expert at understanding students learning styles and the need to be an expert at modifying goals for students learning. School nurses can help support and provide accurate information for teachers teaching family living content, as well as be a resource for discussing topics such as helping patients with HIV infection or accessing current information regarding sexually-transmitted diseases, and facilitating making the information more real and understandable for special education students. School nurses can also support teachers teaching severely handicapped students by being a resource for information about their student population, in finding visual aids and program development and implementation.
\end{abstract}

KEY WORDS: special education, sex education, disability, special day class, Special Education Alternate Curriculum Guide, Health Framework for California Public Schools 


\title{
HOW SPECIAL EDUCATION TEACHERS OF HIGH \\ SCHOOL-AGED STUDENTS ADDRESS SEX EDUCATION
}

\author{
Author Information: \\ Amelia Owen-Casillas, BS, RN \\ MS Candidate, School of Nursing \\ San Jose State University, San Jose CA 95192 \\ Virgil Parsons, DNSc, RN \\ Professor, School of Nursing \\ San Jose State University \\ Daryl Canham, EdD, RN, BC \\ Associate Professor, School of Nursing \\ San Jose State University
}

Contact Information:

Amelia Owen-Casillas

Phone:

email: 


\title{
HOW SPECIAL EDUCATION TEACHERS OF HIGH \\ SCHOOL-AGED STUDENTS ADDRESS SEX EDUCATION
}

\begin{abstract}
In this qualitative pilot study, five special education teachers of high-school-age students responded to seven research questions regarding how they address sex education, a part of family living from the Health Framework for California Public Schools. The participating special education teachers taught either in special education programs for the emotionally-disturbed(ED) or severely handicapped (SH). An overall identified theme for both groups of teachers was family participation. Other themes were teachers needing to be expert at understanding students learning styles and the need to be an expert at modifying goals for students learning. School nurses can help support and provide accurate information for teachers teaching family living content, as well as be a resource for discussing topics such as helping patients with HIV infection or accessing current information regarding sexually-transmitted diseases, and facilitating making the information more real and understandable for special education students. School nurses can also support teachers teaching severely handicapped students by being a resource for information about their student population, in finding visual aids and program development and implementation.
\end{abstract}

KEY WORDS: special education, sex education, disability, special day class, Special Education Alternate Curriculum Guide, Health Framework for California Public Schools 


\section{INTRODUCTION}

As of December 2004, there were 681, 969 special education students in the state of California. There are currently 13 different primary disability categories (California Department of Education, Special Education Division, 2004). Each student in special education has an Individualized Educational Plan (IEP) that lists measurable goals that need to be accomplished by the student. Special Education students with higher skill levels can set goals in the IEP to meet grade level standards. Special education students with lower skill levels may have to attain more developmental skills before they can achieve district grade level standards.

District grade level standards are delineated in the state curriculum (California Department of Education, Curriculum Development and Supplemental Materials Commission). State curriculum is divided into seven frameworks: (a) Reading/Language Arts, (b) Mathematics, (c) Science, (d) History/Social Science, (e) Health, (f) Physical Education, and (g) Visual and Performing Arts. Sex education is a part of the "Health Framework for California Public Schools" (Curriculum Development and Supplemental Materials Commission, 2003) in the content area of family living. Family living promotes the development of positive family interactions in all types of families, including those that face unusual challenges (Curriculum Development and Supplemental Materials Commission, 2003) and also covers sexuality, the reproductive process, contraception, sexually transmitted diseases and their prevention, dating relationships, and the selection of a mate. California Education code, section 51550 (California Education Code, n.d.), states that families receive written notice before the functions of the human reproductive organs are described, illustrated or discussed in school. California Education code, section 51240, permits parents to not have their child participate in sex education.

Special education teachers have available the Special Education Alternate Curriculum Guide for Students with Moderate to Severe Disabilities (SEACG). This curriculum guide breaks down the state framework into four environments: (a) school/ community, (b) domestic, (c) recreational/ leisure, and (d) vocational, so that ideas can be taught in a more concrete, 
applicable way. The SEACG suggests IEP goals and ways that the special education teacher can present subjects and activities for more hands-on learning.

The purpose of this study was to determine whether special education teachers address sex education content in the classroom with their students and whether they develop IEP goals for this

content. Teachers' familiarity with the SEACG and the state curriculum frameworks helped to show whether special education teachers are aware of district grade level standards for their students' grade level.

\section{REVIEW OF THE LITERATURE}

Finding literature regarding special education students receiving sex education in public schools was limited. The focus of information on this topic was not specific to California. Some studies found were from European countries.

Some studies focused on special education teacher training, knowledge and attitudes. May and Kundert (1996) replicated a study that was done previously in 1980 by May to determine if preservice teachers in special education are receiving preparation to teach sex education to their students. Eighty-five percent of questionnaires were returned from chairpersons of special education teaching programs. Fifty-nine percent of programs have coursework regarding preparation for teaching sexuality education; $41 \%$ did not. Sixty-six percent of respondents that did cover preparation for teaching sexuality education reported that the course was a required course; $14 \%$ reported the preparation course for sexuality education was an elective course. The conclusion was that there had been little change in teacher preparation from the 1980 survey to the 1996 survey. Although more programs have required courses in sex education, the actual time spent in class on the topic decreased.

Plaute, Westling and Cizek (2002), from Austria, explored current knowledge and attitudes 
towards the sexuality of persons with cognitive disabilities. A survey of professionals was done using expanded versions of the Sexuality and the Mentally Retarded Attitude Inventory (SMRAI). Individuals with cognitive disabilities were also surveyed using the Interview on the Sexuality of People with Mental Retardation (ISMB) survey by Plaute and Haslauer (2001). The ISMB covered the same items as part four of the SMRAI survey. A third survey was done with educators and residential workers, and a fourth survey with gynecologists who provided services to people with mental retardation. From the results of the surveys, four sex education programs were designed, and the programs were evaluated regarding participant satisfaction. Findings indicated that participants in all group felt knowledge increased with increased participation. The researchers felt the programs were just the first step in addressing needs for populations with cognitive disabilities.

According to Rodriquez, Young, Renfro, Assencio, and Hoffner (1996), in U.S. public schools, the most likely teacher of sexuality education in middle and high schools are physical education teachers, followed by health educators, biology teachers, home economics teachers, and school nurses. Teachers had reported feeling inadequately trained and ill prepared to teach sexuality education and felt in need of assistance with teaching sexuality topics.

Teacher preparation, especially when working with disabled students who are deaf, is needed. Preparation includes training in communication between the teacher and student as well as the teacher and parents. Sexuality education programs for parents of deaf students are just as important as programs for students who are deaf (Getch, Branca, Fitz-Gerald \& Fitz-Gerald, 2001).

Heuttel and Rothstein (2001) found that college students who are deaf have less knowledge about HIV/AIDS than their hearing peers, this indicates that if deaf college students, who are more educated than the general population of people who are deaf, know so much less than their hearing peers, then less educated deaf people would know even less about sexually transmitted diseases that could have devastating effects on their health and longevity.

Other studies focused on the effectiveness of sex education programs for the disabled. The impact of sex education programs on sexual knowledge and feelings of men with a mild 
intellectual disability was done by Garwood and McCabe (2000). This was a qualitative study that examined effectiveness of two sex education programs. The instrument used was the Sexuality Knowledge, Experience, Feelings and Needs Scale for People with Intellectual Disability and was used prior to the programs and afterwards. Minimal increases in posttests were found at the end of the programs.

Caspar and Glidden (2001) created a study conducted as part of a residential services curriculum which focused on improving the sexual knowledge and change of attitudes to allow for better sexual relationships, preserve sexual safety and maintain healthy sexual practices. Participants were 28 to 62 years of age, and consisted of nine females and three males who completed the intervention. Participants responded positively to the interventions. Some participants were referred to the intervention because of inappropriate behavior. All showed progress on the posttests. Some participants had difficulty attending, due to conflicting work hours. One person stated, in response to future presentations, "I don't care when or where you give it, just so long as you keep giving it." The researchers stated that "there is no doubt that adults with DD [developmental disabilities] do not, as a group, have access to a sexual repertoire that is as broad as that of the general population" (p. 176).

A qualitative study by Lesseliers and Van Hove (2002) was completed to "acquire knowledge about the social reality of people with developmental disabilities by closely investigating how such people experience and interpret their own environment and feelings in the context of the relational and sexual lives" (p. 69). Findings from interviews with participants ranging in age from 20 to 60 -years-old found that feeling love and expressing love was difficult to describe. Participants, when asked about exploring the other gender nude or having sexual intercourse would respond with it being "yucky" or "dirty" or "her parents did not want us to do that" or "we are not allowed, our parents are angry with us for doing that." Interviewees described abuses experienced and the inability to get married and have children. They are not allowed to leave their homes to find mates, and they would need permission and "everyone must agree." Most interviewees were unable to name body parts. Women knew names of male genitals, but not their own. They could not say the 
difference between a male and female. Findings of this study indicated that the most important outcome was the ability to discuss their desires, knowledge and experience regarding sexuality and intimate relationships.

Cheng and Udry (2002) examined differences in sexual behavior between physically disabled and non disabled adolescents in the United States. Data were collected from a 1994-1995 Wave 1 data from the National Longitudinal Study of Adolescent Health questionnaire. This study population appeared to be disabled students that were exposed to sex education through the regular education programs and both non disabled and disabled students were similarly exposed to this topic. The average IQ score for the study participants was 95 . This study found that $12 \%$ of girls with disabilities have experienced forced sex, double the figure for non disabled girls. The evaluators also found that the social isolation of the physically disabled and lack of heterosexual interactions resulted in a tendency for same-sex attraction among adolescent boys and girls with mild physical disabilities. Severely disabled adolescents were less romantically attracted to either gender and less certain about preference.

May and Kundert (1996) examined the inclusion of mandated health education and sexuality education in special education school curricula and found that although federal and state laws mandate appropriate educational programs for all children with disabilities, sex education is not included in most students' programs. They discovered information indicating that only $7 \%$ of disabled students had received any sex education in schools. Also, cited by May and Kundert was a study by Brantlinger (1992) which reported that in a study of teachers of students with mild disabilities, only a third of the teachers had offered comprehensive sex education or family life programming and that there was a limited amount of information available on sex education in special education classrooms. Monat (1982) stated that ignorance in sex education can lead to a greater risk that persons with disabilities will be abused, exploited, and exposed to serious health problems (p. 48). Brantlinger (1992) surmised "there is evidence that sexuality instruction is not reaching students in special education classrooms" (p. 40). 
A study by Getch, Branca, Fitz-Gerald and Fitz-Gerald (2001) focused on comprehensive sexuality education, as opposed to just sex education. Comprehensive sexuality education is more than just an understanding of body parts, sexual functioning, or biological sex characteristics. It is more complex than physical descriptions related to gender, because comprehensive sexuality education explains the science of behavior, in terms of sexuality and identity.

Stinson, Christian and Dotson (2002) interviewed 17 disabled women, who reported few or no positive feelings toward their bodies, and their bodies were not regarded as sources of pleasure. The researchers found that when persons with disabilities are seen as helpless and dependent they lose their sense of freedom, self-worth and personal identity as a sexual being; therefore, defeating their ability to attain confidence in being able to be a mother or effective parent.

Other studies examined the lack of sexuality education relative to sexual exploitation. Chamberlain, Rauh, Passer, McGrath and Burket (1984) surveyed female adolescents with mental retardation at a multi service clinic, and found that $25 \%$ of the clients had experienced sexual abuse which was defined as attempted or successful coerced intercourse. Stromsness (1993) found that just under $80 \%$ of women with mild mental retardation interviewed had been sexually abused at least one time. Rindlefeisch and Rabb (1984) found that children living in institutions were found to be abused twice as often as children living at home. Watson (1984) suggests factors that may relate to increased vulnerability may be inappropriate social skills, increased exposure to caregivers and settings, decreased communication skills, not being able to report abuse or seek help, and lack of knowledge on how to defend against abuse.

Another factor is that all staff working in schools are legally mandated reporters, and if they know of, or reasonably suspect child abuse (sexual, emotional, physical or neglect) must report the known or suspected instance to a child protection agency immediately or as soon as is practicably possible. Students need to be aware of inappropriate sexual behavior and that there are laws regarding inappropriate sexual behavior. Because school staff are mandated reporters, the prevention of sexual exploitation and abuse is presented in family life education and reinforces information 
about appropriate and inappropriate behaviors.

Legally, sexual rights are basic human rights. Parents and teachers need to make children aware of their rights and responsibilities regarding their actions toward others. Once children become adults, they become fully responsible for any inappropriate behaviors or non-adherence to laws regarding sexual behavior. In Talk About Sex, by Martha Kempner and Monica Rodriquez (Sexuality Information and Education, 2005), the seven basic human sexual rights are described. The seven sexual rights are: (a) the right to accurate information about sexuality, (b) the right to decide how to express sexuality, (c) the right to make decisions about sexuality, (d) the right to protect yourself from pregnancy and sexually transmitted diseases, (e) the right to say no to unwanted touch, and, (f) the right not to be pressured into sexual activity, (g) the right to stop being sexual with a partner.

\section{METHODS}

This qualitative pilot study used interviews with special education teachers of high-school aged students in both SH and ED programs regarding whether and how sex education was part of their curriculum. Permission for recruiting voluntary teachers was obtained, and teachers signed a consent form before being interviewed, including the willingness to be audio recorded. Teachers from three different sites participated. Data were analyzed from transcribed interviews until no new themes appeared. University Institutional Review Board approval for the study was received and the school programs also granted permission for the study. Participants were provided a $\$ 5$ gift card for their participation.

Seven questions were asked of each participant:

1. How familiar are you with the Special Education Alternative Curriculum Guide for Students with Moderate to Severe Disabilities (SEACG)?

2. How successful have you been in using the SEACG for IEP goal development with your students? 
3. How do you determine whether family living goals are in a student's IEP each year?

4. How do you address sex education for your students?

5. What resources from the SEACG Resource Guide have you found helpful regarding sex education?

6. What frustrations or difficulties have you had with following the state curriculum using the SEACG for sex education for your students?

7. Is there anything else about the SEACG or sex education for your students that you can share?

These questions were developed based on state health framework curriculum used by district regular education teachers, the special education teacher's IEP goal development guide, the SEACG, and a review of the most recent research regarding this topic. A trial interview with a special education teacher who was not part of the study sample helped to determine if the questions were easily understandable.

\section{RESULTS}

One overall theme that was consistent to teachers in both the ED and SH programs was the need for family involvement and agreement regarding the need for discussion of sex education. Teachers expressed that they were aware that parent notification and permission was needed to teach sex education. Teachers also needed to be aware of each student's cultural and religious values, or of any negative past experiences that may make their participation difficult. One teacher expressed that collecting this type of data before covering the topic of sex education was very time-consuming and that there is not a tool that teachers can use to collect this type of data from families.

Two other themes that were identified for the teachers in the SH program were (a) that they needed to be "expert problem-solvers" to adapt material to each student's learning and communication styles so that students could learn and benefit, and (b) that they needed to be "experts at modifying learning goals" so that students would be able to act appropriately to the opposite gender or when in the general public. 
Teachers as "expert problem-solvers" needed to collect information about the student and develop ways of helping the student to accommodate ways to improve abilities when possible. Teachers collect information regarding the student's skills and abilities, medical history and other services used initially from the family. Teachers also acquire current information regarding the student's health from the school nurse or the student's physician. If the student has difficulties with posture or mobility, the teacher would also seek information from the student's therapists, such as occupational or physical therapists. If the student has difficulties regarding speech or chewing and swallowing, the teacher would collect current information about the student's communication skills and abilities and implement current treatments from the speech therapist. If the student has difficulties with recreational or physical education, the teacher would collect current information about the student's current skills and abilities and suggestions from an adaptive physical education specialist. There are also teachers of the visually-impaired who may provide services for students who are legally blind and require suggestions and goals to improve or use strategies appropriate to the students' level of vision. Orientation and mobility specialists aid teachers in understanding and aiding students with limited sight to increase mobility and learn about their surroundings.

A teacher who is an "expert at modifying learning goals" could determine from a student's current skills, perhaps from standardized developmental tool or using the SEACG or district grade level standards or the help of a school psychologist, an appropriate progression of goals, or the next few steps that the student could work towards to progress toward grade level standards or developmental milestones. Goal stem, IEP goal examples listed in the SEACG may give a teacher the idea of how incremental steps could be written that would progress the student's current skill level in a measurable way. An expert teacher at modifying learning goals could also break down grade level standards so that they could be more attainable for the individual. One teacher stated that her sex education related goal for a student was that the student, who was nonverbal and severely cognitively and developmentally delayed, could correctly choose from the symbols outside the 
bathroom which one they should use based on their gender. The teacher could measure that the student understood the meaning of the symbols on the bathroom door by the student choosing the correct door to enter four out of five times over a certain time period.

\section{DISCUSSION}

Teaching family living content can possibly be uncomfortable and overwhelming for special education teachers when so much information and communication are needed regarding past family and student-specific information, material review and consent, and ongoing updates between classroom staff and the student's family. In California, most classrooms have a variety of languages, cultures, and religious values that need to be acknowledged when discussing sex education content. Family information and participation should be encouraged when developing the content to be covered, as well as a viewing of the proposed materials.

Special education teachers need strategies to collect information from families regarding cultural and religious values, such as questionnaires that are specific to family life content. Teachers also need assistance and support to develop materials that will serve the culturally and religiously diverse group of students. Teachers with nonverbal students need verbal and visual methods to model ideas for students. More programs are needed that provide strategies for teaching the nonverbal or developmentally-delayed student populations.

Teachers in California need to collect information from families that do not speak English. Family collaboration is difficult when families and teaching staff cannot communicate easily. This limits communication with the family and makes understanding one another more difficult. Programs that cover the state framework and are specific to the 13 primary disability categories in special education are needed to help special education teachers in providing sex education to the SH and ED program population.

Students in programs for the emotionally-disturbed may have been exposed to disturbing experiences in the past. Some may not be able to participate in sex education programs if they find it 
upsetting because of prior abuse. Special education teachers in this program are sensitive to students' previous traumatic experiences and make accommodations for students' non-participation or who choose to work with their therapists in a confidential setting rather than in a classroom when sensitive issues are discussed.

Mental health therapists address difficult emotional areas with students in programs for emotionally-disturbed children and help students to cope and problem-solve more effectively. However, it is not clear whether sex education or information is discussed with students by the students' mental health therapists in programs for emotionally disturbed children.

\section{IMPLICATIONS FOR SCHOOL NURSING PRACTICE}

School nurses are part of the special education consultative model with many resource staff that can be called upon by the teacher to help them to teach the students. School nurses can assist teachers in developing a family life program that provides current factual data and accurate visual aids. School nurses can also help teachers in finding speakers in the community that cover family life topics.

School nurses working with the special education student population know the importance of preparing students for making improved decisions regarding appropriate behavior, positive family interactions, contraception, and the prevention of sexually transmitted diseases. The state health education framework provides special education teachers and school nurses the structure for presenting this material; the difficulty is in finding methods of communicating and presenting the material so it is comprehended by special education students and families of the culturally, religious, and lingually diverse special education population in California public schools. 


\section{REFERENCES}

Brantlinger, E. (1992). Sexuality education in the secondary special education curriculum: Teacher's perceptions and concerns. Teacher Education and Special Education, 15, 32-40.

California Department of Education. Curriculum Development and Supplemental Materials Commission. [Data file]. Available from Web site, www.cde.ca.gov/ci/cr/cf/index.asp.

California Department of Education, Special Education Division. (2004). Special education enrollment by age and disability-statewide report, 2004. [Data file]. Available from Web site, http://data1.cde.ca.gov/dataquest/SpecEd1.asp?cChoice=SpecEd1\&cYear=2004005\&cLevel $=$ State\&myTimeFrame $=$ S\&submit $1=$ Submit $\&$ ReptCycle=December

California Education Code. (n.d.). Retrieved November 25, 2003, from http://www.cde.ca.gov/cyfsbranch/lsp.health/Links.htm

Caspar, L .A., \& Glidden, L. M. (2001). Sexuality education for adults with developmental disabilities. Education and Training in Mental Retardation and Developmental Disabilities, 36, 172-177.

Chamberlain, A., Rauh, J., Passer, A., McGrath, M., \& Burket, R. (1984). Issues in fertility control for mentally retarded female adolescents: Sexual activity, sexual abuse, and contraception. Pediatrics, 73, 445-450. 
Cheng, M. M., \& Udry, J. R. (2002). Sexual behaviors of physically disabled adolescents in the United States. Journal of Adolescent Health, 31, 48-58.

Curriculum Development and Supplemental Materials Commission. (2003). Health framework for California public schools: Kindergarten through grade twelve. Retrieved October 24, 2003 from http://www.cde.ca.gov/ cdepress/downloads.html

Dombrowski, S. C., Ahia, E., \& McQuillan, K. (2003). Protecting children through mandated child-abuse reporting. The Educational Forum, 67, 119-127.

Garwood, M., \& McCabe, M. P. (2000). Impact of sex education programs on sexual knowledge and feelings of men with a mild intellectual disability. Education and Training in Mental Retardation and Developmental Disabilities, 35, 268-283.

Getch, Y. Q., Branca, D. L., Fitz-Gerald, D., \& Fitz-Gerald, M. (2001). A rationale and recommendations for sexuality education in schools for students who are deaf. American Annals of the Deaf, 146, 401-408.

Heuttel, K .L. \& Rothstein, W. G. (2001). HIV/AIDS knowledge and information sources among deaf and hard of hearing college students. American Annals of the Deaf, 146, 280-286. 
Lesseliers, J. \& Van Hove, G. (2002). Barriers to the development of intimate relationships and the expression of sexuality among people with developmental disabilities: Their perceptions. Research and Practice for Persons with Severe Disabilities, 27, 69-81.

May, D. C., \& Kundert, D. C. (1996). Are special educators prepared to meet the sex education needs of their students? A progress report. The Journal of Special Education, 29, 433-441.

Monat, R. (1982). Sexuality and the mentally handicapped. San Diego: College-Hill Press.

Plaute, W., \& Haslauer, B. (2001). Wissen und Einstellung von Menschen mit geistiger Behinderung im Bereich von Sexualitaet und Aufklaerung. Unpublished manuscript.

Plaute, W., Westling, D. L., \& Cizek, B. (2002). Sexuality education for adults with cognitive disabilities in Austria: Surveys of attitudes and the development of a model program. Research \& Practice for Persons with Severe Disabilities, 27, 58-68.

Rindlefeisch, N., \& Rabb, J. (1984). How much of a problem is resident mistreatment in child welfare institutions? Child Abuse and Neglect, 8, 33-40.

Rodriguez, M., Young, R., Renfro, S. Assencio, M., \& Hoffner, D. (1996). Teaching our teachers to teach: A SIECUS study on training and prep for HIV/AIDS prevention and sexuality education. [Online] Available at: www.siecus.org./pubs/teach/teac0001.html 
17

Sexuality Information and Education Council of the United States. (2005). Talk about sex (and ed.) [Booklet]. Kempner, M. \& Rodriguez, M.: Authors.

Stromsness, M. M. (1993). Sexually abused women with mental retardation: Hidden victims, absent resources. Women and Therapy, 14, 139-152.

Stimson, J., Christian, L., \& Dotson, L.A. (2002). Overcoming barriers to the sexual expression of women with developmental disabilities. Research \& Practice for Persons with Severe Disabilities, 27, 18-26.

Watson, J. D. (1984). Talking about the best kept secret: Sexual abuse and children with disabilities. The Exceptional Parent, 14, 15-20. 